\title{
Relationship Priorities and the Australian Marriage Divide
}

Liz van Acker

Griffith University

\section{Introduction}

The Australian government regards couple relationships/marriage as one of the foundations of society, the best place to raise children and good for people's wellbeing. Nevertheless, marriage is inherently unstable. Consequently, governments confront the difficulty of where and how to allocate resources when attempting to strengthen family relationships, raising questions about when to intervene on the relationship spectrum. The federal government wishes to develop strong foundations for family wellbeing and to reduce the costs of family breakdown calculated at \$3 billion per year (Department of Social Services, 2014). The public purse funds a range of services and support for families, with most attention on post-separation services that assist in reducing conflict and protecting the family unit and children (Parkinson, 2011). The government also funds programs such as the Stronger Relationships trial which provides counselling or a \$200 'marriage voucher' for any couples in a committed relationship including same-sex couples (even though they are not permitted to legally marry). This paper contributes to the discussion about this marriage divide by exploring programs targeting couple relationships that are not in distress. As a 'social investment', couple relationship education (CRE) is different from 'late' intervention for couples going through separation and divorce. CRE encompasses early intervention measures that aim to enhance and strengthen relationships.

The paper provides a policy analysis of how federal governments have been implementing strategies to address marriage and to strengthen couple relationships. It examines CRE as a policy response to changes in couple relationships that contribute to the marriage divide. It traces the development of CRE since the 1960s. Incremental approaches have ensued, regardless of a few financial boosts at various times when influence and opportunities for expanding preventative programs occurred. Overall, however, governments have directed spending to programs which assist in reducing conflict during separation and divorce. I argue that while government policies must address issues such as family dispute resolution, there are policy challenges here which may exacerbate the marriage divide.

\section{The Potential of CRE}

CRE is an early preventive and intervention program providing structured education to couples about relationship knowledge, attitudes and skills. CRE may assist in sustaining healthy, mutually satisfying relationships, and in reducing relationship distress and separation (Halford et al., 2008). The interaction between partners is the strongest predictor of relationship satisfaction (Bradbury and Karney, 2004). Little effort in nurturing the relationship strongly predicts further deterioration in relationship satisfaction (Halford et al, 2007). Poor communication and negativity also foresees deterioration in couple satisfaction 
(Johnson et al, 2005). CRE aims to reduce or eliminate the decline in relationship satisfaction over time and could benefit high-risk couples if the risks themselves are recognized (Bradbury and Lavner, 2012). Unlike counselling or therapy which offer support for distressed couples, CRE's objective is to assist couples moving through the various phases of their relationship.

\section{Government Interventions in Marriage}

The marriage divide has triggered anxieties about when, where and how to deliver relationship support. Consequently, CRE has received less priority than other programs. The Marriage Act (1961) introduced strategies to support stable marriage and families. The Family Services Program (FSP) delivered programs via the Churches and secular organizations working with educators and social workers. This involved marriage preparation, family skills training and parenting; marriage counselling; and programs aimed at harmonious separation and family mediation (HRSCLCA, 1998). The greatest demand for government services involved high-conflict situations. Funding for marriage education programs gradually increased, pursuant to provisions in the Family Law Act 1975. Section 43 includes legal principles of supporting marriage, stating that the Family Court shall have regard to 'the need to preserve and protect the institution of marriage as the union of a man and a woman to the exclusion of all others' to assist married couples with 'the improvement of their relationship to each other'. 1976 was a landmark year for the development of marriage support because the AttorneyGeneral increased support for pre-marriage education as a preventative approach to the growing levels of marital breakdown. Employing trained, professional staff heralded the government as a new and active influence on the programs (Harris et al., 1992: 13). By the 1980s there was an expansion of adult education with courses teaching communication skills and conflict resolution. Pre-marital education was developing into an instructive practice in its own right and responding to increasing community, church and government concerns for marrying couples (Harris et al., 1992: 12-3). Inventories such as FOCCUS and PREPARE allowed couples to answer questions about their relationships and then discuss any relevant concerns with a facilitator.

Public money for early intervention programs was not particularly generous under the Hawke/Keating Labor government (1983-1996). For instance, in 1989-90, it provided \$248,000 to 24 agencies (Andrews and Andrews, 1997, p. 111). By the 1990s, the divorce rate had increased, fewer couples were marrying and more were cohabitating. Various committees reviewed marriage education programs and services, calling for early intervention and prevention. For example, the 1992 Joint Select Committee on Certain Aspects of the Operation and Interpretation of the Family Law Act (para 4.97) supported,

a compelling cost benefit argument in favour of more funding for preventative education, which might help reduce the number of marriages which reach the stage of breakdown. Successive governments have given this field far too low a priority for funding ... immediate actions should be taken to rectify this situation.

Nevertheless, the Labor government was reluctant to prioritise preventative programs and there was little information about their effectiveness. By the early 1990s it provided just $\$ 500,000$ annually towards CRE. In 1994-95, 28,173 
people, three-quarters of whom were couples utilized marriage education (Andrews and Andrews, 1997, 113). Labor increased funding in 1995, but the Opposition promised to double it.

In 1996, the new Liberal National Coalition government was anxious about the decline in marriage and increasing divorce rates. Its report To Have and to Hold: Strategies to Strengthen Marriage and Relationships (1998) recommended preventive strategies as a pragmatic way of coaching people about marriage (HRSCLCA 1998, 67). The government expanded funding to \$4 million per annum via the Family Relationships Services Program. One aim was to increase the participation rate of 30 percent: couples tended to be white, middle-class, religious and did not cohabitate. This aim has not been successful, due to the increase in civil ceremonies where couples tend not to consider CRE (Andrews, 2012).

The issue of government intervention in the marriage divide re-emerged in response to a parliamentary inquiry into Australia's custody laws in 2003. Fathers' groups lobbied for men's rights and greater access to children postseparation. In 2005, the government invested \$397.2 million in the family law system. The new Family Relationship Centres (FRCs) allocated most of their funding for separating couples, family dispute resolution and the 'problem' end of the relationship spectrum rather than intact families (Moloney et al, 2013). Service providers commented that 'preventative' meant working with separating couples and that the FRCs were the 'ambulance at the bottom of the cliff', offering intervention after the damage had been done (cited in van Acker, 2008, 106).

The Rudd/Gillard Labor governments increased family relationship support funding by $\$ 277$ million from 2008 to 2011. There was, however, no specific attention to CRE which continued but did not expand until the conservative Abbott government's Stronger Relationships \$20 million scheme in 2014. The Opposition leader Bill Shorten questioned the government's marriage priorities while cutting funds for schools, child care and visits to the doctor (Chalmers, 2014). Budget reductions were also announced for pensions, unemployment and disability benefits. Tensions surrounding the place of CRE continue as the government attempts to regulate various aspects of the marriage divide.

\section{Discussion}

There are three major challenges in developing CRE as a way of addressing the 'marriage divide' in the policy area of strengthening family relationships. First, most participants are white, middle class and educated, while vulnerable couples at higher risk of confronting relationship difficulties are underrepresented in CRE (Halford et al, 2006). Ethnic groups, Aboriginal and Torres Strait Islanders, lowincome families or those on welfare or living in remote or rural communities, step-families and people experiencing substance abuse, mental illness or disability are the least likely to access early intervention and preventive measures (Simons and Parker, 2002; Catholic Welfare Australia, 2006). They are less likely to obtain support funded under the FSP (Department of FaHCSIA, 2012). Domestic violence and conflicts over financial difficulties add to relationships distress. Low participation by at-risk groups raises the problem that relationship strengthening 
programs are not connected to economic policies around alleviating poverty, reducing unemployment and improving work family balance that impact on the well-being of couples and families.

Second, Australian evaluations of the long-term effects of CRE are scarce, but would be extremely useful in gathering data about the efficacy of programs. International studies illustrate that CRE of approximately 12 hours can improve communication skills and relationship quality, thereby strengthening relationships over a period of one to five years (Stanley et al, 2006, Hawkins et al, 2008, Halford, 2011). There are improvements in observable relationship skills such as problem-solving and positive effects in communication skills, especially for wellfunctioning couples (Blanchard et al, 2009). Regardless of specific curriculum content, the act of participating in CRE with one's partner may have a positive effect on commitment (Hawkins et al, 2012). UK research found that marriage and relationship education resulted in positive changes in people's relationship quality, wellbeing and communication (Spielhofer et al, 2014). Nevertheless, we need to know more about whether couples can apply complex new skills learned in these programs in their everyday life (Blanchard et al, 2009). It is especially important to gain knowledge about the effectiveness of CRE for step-families, low-income, non-English speaking and other at-risk groups. More systematic knowledge is required about how to work with couples whose relationships function relatively well, but confront difficult family backgrounds, aggression and stress (Bradbury and Lavner, 2012).

Third, people who could benefit from the programs may be unaware of them or their usefulness. The trial response has been reasonable with 2982 couples applying for vouchers in the five weeks of the Stronger Relationships offer. Cohabitating couples may perceive CRE as unnecessary (although these are the people who are most likely to separate). A related obstacle is people's disinterest and perceptions that they will be 'preached at' (van Acker, 2008). The success of CRE depends on increasing people's accessibility to services, raising awareness and motivating couples to participate.

\section{Conclusions}

As far as the marriage divide goes, governments have a limited role in influencing people's relationship choices and cannot regulate or persuade them to marry; they can merely finance programs which they hope couples will use, whether they be prevention programs such as CRE or programs targeting the problem end of relationships involving counselling, therapy and mediation. CRE tends to attract partners who are healthy, well-off and educated. If those on a low income confront unemployment or have inadequate access to good quality housing, education and health care, participating in voluntary programs such as CRE, developing stable relationships and getting married may not be feasible. Moreover, this cohort's relationships may be under stress precisely because they do have insufficient resources necessary for socioeconomic security.

Policymakers need thorough evaluations of CRE conducted in Australia. If findings are positive, advertising the benefits could encourage more involvement. While some couples are open to participating in adult education programs such as 
CRE, attitudinal barriers to accessing the programs include the belief that adults 'naturally' know how to be good partners and do not need early preventative measures to develop relationship skills. Many couples expect a fairy tale ending and do not want 'counselling', or they confront a range of life challenges so that CRE is not an important consideration. They do not want governments interfering in their personal lives, unless or until they require financial support or legal assistance when relationships are in trouble.

\section{References}

Andrews, K, 2013, Maybe 'I do': Modern Marriage and the Pursuit of Happiness, Ballan: Connor Court.

Andrews, K and Andrews, M, 1997, Strategies to Strengthen Marriage: The Australian Experience, Family Impact Seminar Strategies to Strengthen Marriage: What Do We Know? Papers presented at a Roundtable Meeting, Washington, DC.

Blanchard, V, Hawkins, A, Baldwin, S and Fawcett, E, 2009, Investigating the effects of marriage and relationship education on couples' communication skills: A meta-analysis study, Journal of Family Psychology, 23, 203-214.

Bradbury, T and Karney, B, 2004, Understanding and altering the longitudinal course of marriage, Journal of Marriage and the Family, 66, 862-879.

Bradbury, T and Lavner, J, 2012, How can we improve preventive and educational interventions for intimate relationships, Behavior Therapy, 43, 113122.

Catholic Welfare Australia and the Australian Department of Families, Community Services and Indigenous Affairs, 2006, Lessons from the Field: Family Relationships Services in Rural and Remote Australia - Challenges and Good Practice. Canberra: Department of FACSIA.

Chalmers, L, 2014, 'Federal Government offers newlyweds \$200 voucher to attend marriage counselling', Courier Mail, 23 January.

Department of FaHCSIA, 2012, Family Support Program Future Directions Discussion Paper, Canberra.

Department of Social Services, 2014, Stronger Relationships Trial, http://www.dss.gov.au/our-responsibilities/families-and-children/programs-servic ces/stronger-relationships-trial/stronger-relationships-trial-frequently-asked-quest ions-for-couples\#2

Halford, K, 2011, Marriage and relationship education: What works and how to provide it, New York, Guilford.

Halford, K, O’Donnell, C, Lizzio, A and Wilson, K, 2006, Do couples at high risk of relationship problems attend premarriage education?, Journal of Family Psychology, 20, 160-63.

Halford, K, Markman, H and Stanley, S, 2008, Strengthening couple relationships with education: Social policy and public health perspectives, Journal of Family Psychology, 22, 497-505.

Hawkins, A, Stanley, S, Blanchard, V and Albright, M, 2012, Exploring Programmatic Moderators of the Effectiveness of Marriage and Relationship Education Programs: A meta-analytic study, Behaviour Therapy, 43, 1, 77-87.

Hawkins, A, Blanchard, V, Baldwin, S, and Fawcett, E, 2008, Does marriage and relationship education work? A meta-analytic study, Journal of Consulting and Clinical Psychology, 76, 723-734. 
House of Representatives Standing Committee on Legal and Constitutional Affairs, 1998, To Have and to Hold: Strategies to Strengthen Marriage and Relationships, Canberra, Commonwealth of Australia.

Johnson, M, Cohan, C, Davilla, J, Lawrence, E, Regge, R and Karney, B. et. al 2005, Problem-solving skills and affective expression as predictors of change in marital satisfaction, Journal of Consulting and Clinical Psychology, 73, 15-27.

Moloney, L, Qu, L, Weston, R and Hand, K, 2013, 'Evaluating the Work of Australia's Family Relationship Centres: Evidence from the First 5 years', Family Court Review, 15, 2, 234-249.

Parkinson, P, 2011, For Kids' Sake: Repairing the Social Environment for Australian Children and Young People, Vos Foundation.

Simons M and Parker R, 2002, A Study of Australian Relationship Education Service Activities. Canberra: Department of Family and Community Services.

Spielhofer, T, Corlyon, J, Durbin, B, Smith, M, Stock, L and Gieve, M, 2014, Relationship Support Interventions Evaluation, London, Department for Education.

Stanley, S, Amato, P, Johnson, C and Markman, H, 2006, Premarital education, marital quality, and marital stability: findings from a large, random, household survey. Journal of Family Psychology, 20, 117-126.

van Acker E. 2008, Governments and Marriage Education Policy: Perspectives from the UK, Australia and the US. Basingstoke, Palgrave Macmillan. 